\title{
MODELLING DYNAMICS OF THE TALC WITH SYSTEM DYNAMICS METHODOLOGY AND DPSIR FRAMEWORK
}

\author{
Marko Hell
}

https://doi.org//10.20867/tosee.06.23

\begin{abstract}
Purpose - touristic destinations develop over time, which is why, in order to get a comprehensive picture of their development, it is necessary to observe it's dynamics.

Methodology - in this paper system dynamics methodology and of DPSIR framework will use. In order to model reasoning behind the TALC behaviour, presented research in this paper leans on TALC logistic curve.

Findings - deeper analysis of the causes and/or consequences elements of destination (sub)system (supply and demand) will indicate way of affect touristic area life cycle dynamics.

Contribution - better understanding of the background structure of TALC pattern behaviour may help destination managers/planners to bring appropriate policies to move destination's sustainability towards higher level of organisation.
\end{abstract}

Keywords: TALC logistic curve, TALC pattern behaviour, system dynamics, DPSIR, policies.

\section{INTRODUCTION}

The Tourism area life cycle model (TALC) (Butler 1980) has recently become one of the most cited models in tourism literature. The purpose of the TALC model, as explained by Butler (Butler 2006), was primarily to draw attention to the dynamic nature of destinations and to propose a generalised process of development and potential decline which could be avoided with the appropriate interventions (planning, management and development). Hence, it can be said that it represents only a statistical approximation. It describes the evolution of a tourist area through six stages (Figure 1), namely, the "exploration", "involvement", "development" and "consolidation", signifying growth expressed in number of visitors, while the "stagnation" stage represents a gradual decline. The end of the cycle is marked by the "post-stagnation" stage, which comprises a set of five options which destination may follow (Muller et al. 2010). 
ToSEE - Tourism in Southern and Eastern Europe, Vol. 6, pp. 343-356, 2021. M. Hell: MODELLING DYNAMICS OF THE TALC WITH SYSTEM DYNAMICS METHODOLOGY ...

Figure 1: Hypothetical Tourism Area Life Cycle

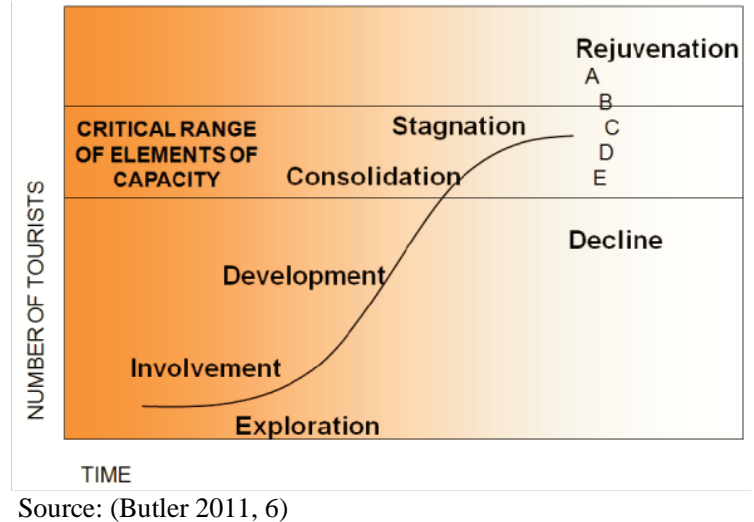

As for the variable indicating the change along the lifecycle stages, to characterize the change of the destination in terms of life cycle stages, Haywood (Haywood 1986) considers the variation in the number of tourists. According to him, the destination could be in the decline stage if there is a sustained decline of about half a standard deviation, while the development stage would be the result of an increase of the same magnitude. If there is a decline in arrivals of less than one-half of a standard deviation, the destination would enter the stagnation stage. An increase of less than half a standard deviation would place the destination in the consolidation stage. Di Benedetto and Bojanic (Di Benedetto and Bojanic 1993) used the number of tourists as the measure in their model. In addition, they augmented it with a "dummy variable" that captured the influences of the environment, revitalization, and the influence of new attractions. Examples include the fuel crisis of 1974 and 1979, the World's Fair, the EPCOT Center, and the Cuban missile crisis.

Some authors use accommodation capacities as a kind of proxy for investments in a destination's tourism (Cole 2012) or monthly bed-night data as a measure of demand (Karplus and Krakover 2005). However, Cruz and Peñarrubia Zaragoza do not consider it as an appropriate indicator of saturation unless related to the level of tourist satisfaction (Cruz and Peñarrubia Zaragoza 2019). The stages of tourism development in the regions of Southwestern Europe were identified by Romão et al. who developed a simplified tourism life cycle model. They used growth rate of nights spent by tourists and Location Quotient (associated with the employment in hotels and restaurants) as a measure of importance of economic activities related to tourism (Romão et al. 2013). The same information was adopted as indicator in a panel data model, together with other variables concerning sustainability (regional, natural, and cultural resources), regional innovation efforts, and other elements associated with tourism infrastructure and economic conditions affecting regional tourism performance. In order to remove negative effect of perception excessive demand Diedrich and Garcia-Buades explore residents perceptions about impact of tourism activities (Diedrich and Garcia-Buades 2009). They obseverd tourism activities as signals of evolution of toursim destinations. 
ToSEE - Tourism in Southern and Eastern Europe, Vol. 6, pp. 343-356, 2021.

M. Hell: MODELLING DYNAMICS OF THE TALC WITH SYSTEM DYNAMICS METHODOLOGY ...

An equally important issue in the elaborated papers is the number of stages a destination passes during its lifetime. With this regard, it was pointed out that the existence of a variety of non-S-shaped curve patterns implies that there are alternatives to the traditional stages to the tourist area life cycle already (Haywood, 1986). Moreover, Haywood said that even those who accepted the S-shaped curve as the dominant pattern of the touristarea cycle-of-evolution identified a varying number of stages and labels for these stages. Thus, Dealbuquerque and McElroy suggest that Caribbean islands pass through three primary stages of tourist development: low-density exploration, rapid growth and consolidation, and high-density maturation involving the substitution of man-made for natural attractions (Dealbuquerque and McElroy1992).

Prideaux argues that a new approach to the issue of resort development is required and proposes a new model, the Resort Development Spectrum, with the four life cycle stages (Prideaux 2000). "Simplified" version of the TALC model, suggest three staged TALC model (Romão et al. 2013). They establish three criteria for measuring changes in each phase. The stage of exploration concerns the regions whose growth rate is low or negative. There, the degree of specialization was calculated by the LocationQuotient, which takes into account employment in hotels and restaurants. If the destination has a large tourist demand, it marks the development stage. Finally, if the growth rates are low while tourism plays an important role in the economy, the regions with higher specialization in tourism activities are characterized by stagnation.

To better explain the behaviour of the TALC model, figure 2. present life cycle stages based on the number of tourist arrivals in the city of Split as a case, in the period from 2007-2019. The curve delineating behaviour of demand has sigmoid shape. In addition, it can be divided in shorter time-periods (from 2009-2011 and 2011-2019) resulting again with two sigmoid curves. This potentially indicates existence of a rule, common to all similar situations.

Figure 2: Yearly number of visitors in Split

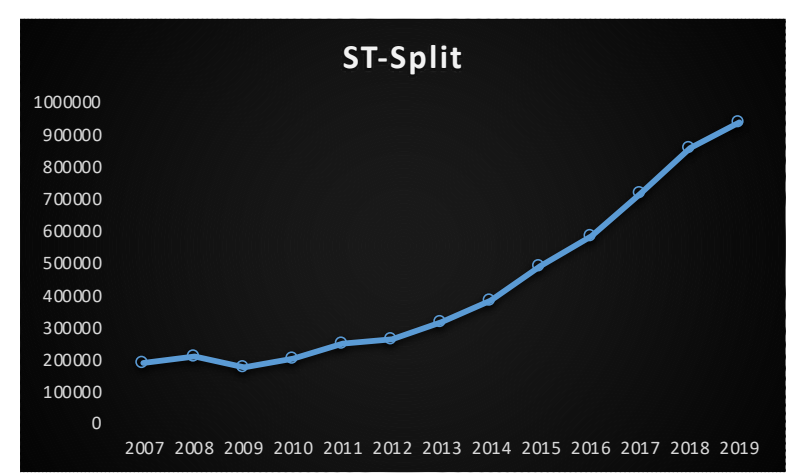

Source: adjusted to (Petrić et al. 2020) 
ToSEE - Tourism in Southern and Eastern Europe, Vol. 6, pp. 343-356, 2021.

M. Hell: MODELLING DYNAMICS OF THE TALC WITH SYSTEM DYNAMICS METHODOLOGY ...

According to previous, this paper ${ }^{1}$ aims to propose a structure of TALC model, including both, demand and supply side to delineate life cycle stages. Furthermore, is common fact that any tourist destination is a complex adaptive system, and as such possesses a structure spanning several scales or layers with a (sub)structure at every scale and involves interplay between cooperation and competition (Baranger 2000). As pointed by Baggio, complexity is the study of the structures which depending only partially on the nature of their constituents and concerns the unforeseen adaptive capacities and the emergence of new properties in systems that arise as the quantity and the quality of the connections among individuals and organisations increase (Baggio 2008). In line with the aforesaid, it can be said that the main goal of this paper is to examine and describe the structure of the TALC pattern behaviour. Given this, it will hopefully contribute to the interdisciplinary understanding of sustainability at the community (and other levels) by drawing attention to cross-scale relationships. Finally, to explain the logic lying behind the TALC model outlined in this paper, the system dynamics (as an aspect of systems theory) will be employed to comprehend how information feedback governs using feedback loops, and stocks and flows. Following the theoretical explanation on system dynamics, a structure of TALC model is being improved with DPSIR (Drivers, Pressures, States, Impacts and Response) framework for better systematizing sustainability indicators (Siwailam et al., 2019). Further TALC research will be conducted towards the analysis of the structure of cause-consequence links among elements of a destination (tourist area) system in the context of DPSIR. This means that the destination as a system will be further split into subsystems, each one of them specifically behaving, and while interacting with each other, shaping the destination's life cycle stages.

\section{METHODOLOGY}

\subsection{System Dynamics}

The term "life cycle assessment" (LCA) was first used in the late 1980s to describe holistic environmental assessments. Since its introduction, more than a hundred of studies have been conducted. Few of these have consistent methodological approaches or use equivalent data and assessment criteria. It is therefore relatively easy to criticize LCA studies. Critiques of LCA studies have therefore been relatively easy to mount. "Some of the prevailing problems are put down to the immaturity of the technique (data and allocation problems), whereas others may turn out to be less tractable (impact assessment and evaluation)" (Berkhout 1996, 146).

\footnotetext{
1 "This article is based on research done in the context of the SmartCulTour project that has received funding from the European Union's Horizon 2020 Research and Innovation Programme under grant agreement no. 870708. The authors of the article are solely responsible for the information, denominations and opinions contained in it, which do not necessarily express the point of view of all the project partners and do not commit them"
} 
ToSEE - Tourism in Southern and Eastern Europe, Vol. 6, pp. 343-356, 2021. M. Hell: MODELLING DYNAMICS OF THE TALC WITH SYSTEM DYNAMICS METHODOLOGY ...

Figure 3: Basic concept of calculation

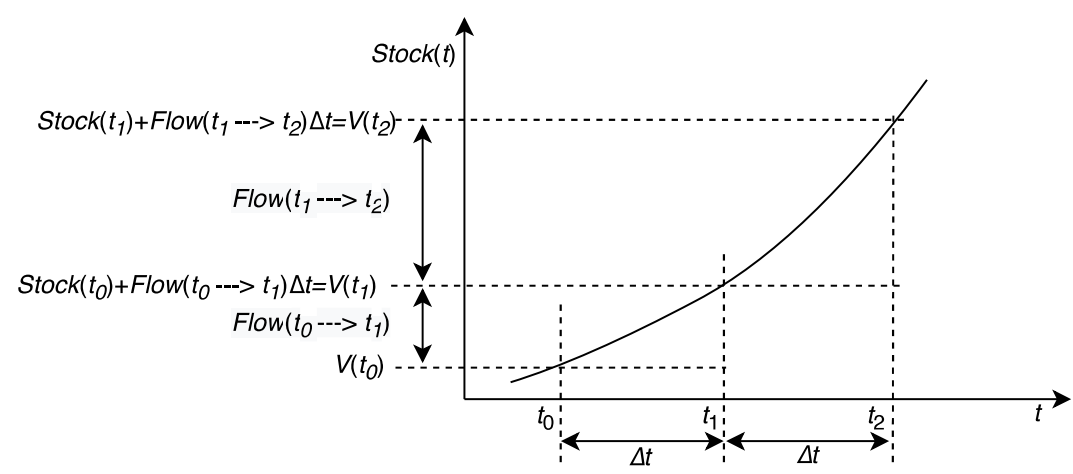

Source: (Hell and Petrić, 2021)

As already explained, the lifecycle model represents only a statistical approximation. However, system dynamics methodology can be used for analysing structure of lifecycle patterns. The system dynamics uses Parametric and structural assumptions have used in order to modelling behaviour of system (Sterman 2000). A practical system dynamics analysis generally requires creation of a structure of the observed problem in order to understand how that structure generate that problem (Schoenberg et al. 2020). Also, it aims to understand how to improve that structure in order to explain the reasons why the observed behaviour has been generated (Richarson 1996). Based on this, the practitioner may propose changes of models that will cause more favourable behaviour (Richarson 1981).

The system dynamics mathematical models are generally presented by two types of functions: stock and flow variable. These two variables make level equation (1), representing the basic element of a system dynamics model.

$$
\operatorname{Stock}(t)=\operatorname{Stock}\left(t_{0}\right)+\sum_{i=1}^{n}\left(\operatorname{inflow}\left(t_{i}\right)-\operatorname{outflow}\left(t_{i}\right)\right) \cdot \Delta t
$$

A stock is measured at the certain point of time, and represents an existing quantity which may have accumulated in the past. A flow (inflow/outflow) variable is measured over an interval of time. Therefore, a flow would be measured per unit of time (such as a year). Flow is roughly analogous to the rate or speed in this sense. This means that level functions may be calculated in one-time period, while two-time periods are needed to calculate rate function (figure 3.). In order to better understand the structure of calculation, figure 4 presents cause-consequence structure diagram of level function described by expression (1).

Figure 4: Cause-consequence structure diagram of level function<smiles>COCC(C)[GeH2][SeH2]</smiles>

Source: adjusted to (Hell and Petrić, 2021) 
ToSEE - Tourism in Southern and Eastern Europe, Vol. 6, pp. 343-356, 2021.

M. Hell: MODELLING DYNAMICS OF THE TALC WITH SYSTEM DYNAMICS METHODOLOGY ...

Figure 4 shows the causal relationships with their signs $(+$ and -$)$ indicating direction and effects of an action (proportionality / inverse proportionality).

Key constituents of the system dynamic models are feedback loops and delays that serve to connect data in an interactive manner, in accordance with the internal logic of the observed system. All dynamic models were controlled by two types of feedback loops, each one of them behaving in a specific manner (Richardson and Pugh 1981). Positive feedback loops amplify the momentum of action, while negative feedback loops limit action, consequently regulating the system. An example of each type of loops may be associated with the basic equation describing typical behaviour of the Butler's original TALC model.

\subsection{DPISR framework}

Berkhout pointed two important questions in the context of life cycle assessment (Berkhout 1996, 145):

- "How significant is each of the impacts that a system generate in the environment?", and

- "What are the most effective means of reducing these impacts?"

Furthermore, in the context of tourism, Butler stressed that the TALC model had, at its core, the belief that if demand and visitation exceeded the capacity of the destination, then the quality of experience for visitors, quality of life for residents and the destination's physical appearance would suffer, consequently causing the loss of attractiveness, and decline in number of visitors (Butler 2006). In order to analyse impacts of tourism activity in context of TALC, in this paper DPSIR (Driver Forces, Pressures, States, and Responses) framework will be employed. With this "valuable tool" complex environmental issues can be organized and communicated (Bradley and Yee 2015). The DPSIR framework was developed by the European Environmental Agency, has been used by the United Nations, and has been adopted by the US Environmental Protection Agency (EPA) in the Sustainable Puerto Rico initiative. The DPSIR framework is a systems-thinking framework. It means that DPISR framework observed cause-effect interaction between subsystems (e.g. social, economic, and environmental) of underlying system like touristic destination. The framework can be summarized as follows (Bradley and Yee 2015):

- Driving Forces are the factors that motivate human activities and fulfil basic human needs. Driving Forces describe "the social, demographic, and economic developments in societies" (Gabrielson and Bosch 2003). Driving Forces use resource and on that way make pressure. They may be observed as two divided subsystems into Economic Sectors and Social Driving Forces.

- Pressures are defined as human activities that result from the operation of social and economic drivers. These cause changes in the environment or in human behaviour that may affect human health. Pressures are also devided into two separate subsystems: Environmental Pressures and Human Behaviour Pressures. 
ToSEE - Tourism in Southern and Eastern Europe, Vol. 6, pp. 343-356, 2021.

M. Hell: MODELLING DYNAMICS OF THE TALC WITH SYSTEM DYNAMICS METHODOLOGY ...

- State refers to the state of the natural and built environment (Gabrielson and Bosch 2003) and human systems (Yee et al. 2012). With this regards, State has two subsystems: Environmental and Human systems state.

- Impacts are the measure of the ecosystem functioning on the welfare of humans, including the production of ecosystem goods and services and ultimately, human well-being. Impacts are divided into the two subsystems: Ecosystem Services and Human Well-being. Ecosystem Services has effect on human system state.

- Responses are defined as set of actions taken by some actors in order to adapt system to changes.

The framework describes structure of development as cause-consequence chain. The division of indicators into subsystems allows policy makers to provide feedback on environmental quality and the resulting impact of policy decisions made or to be made in the future.

The DPSIR framework has been commonly used in sustainable development literature (Bradley and Yee 2015). DPSIR used for sustainable environmental and socioeconomics management of freshwater ecosystem service (Koundori et al. 2016) and to evaluate sustainability in coastal area (Bidone and Lacerda 2004). Odermatt used DPSIR for meta-analysis of sustainability in mountain regions (Odermatt 2004), while Atkins focused on the management of marine environment (Atkins et al. 2011). As shown by Haberl, it is also possible to use it in order to improve the understanding of socioeconomic biodiversity pressures and drivers (Haberl et al. 2009).

The application of DPSIR covers also the field tourism research. In order to investigate the sustainability of tourism development in the selected Mediterranean regions (Pivčević et al. 2020) have used DPSR to analyse its similarities and differences

The DPSIR framework creates a set of stable indicators that are used as a basis for analysis. However, it does not take into account the dynamical change of the system in question (Pivčević et al. 2020), and this is one of the critiques. As Karageorgis emphasizes, in order to understand the cause-effect relationship for a given environmental problem, one should focus on the connections among the distinct categories (DPSIR) (Karageorgis et al. 2006). Given the above, the use of system dynamics approach in the context of DPSIR framework seems to be very appropriate. It can be employed in order to model constraints, which cause limitations in TALC. DPSIR framework enables illustrating the complexities of the system interactions in TALC, especially for analysing demand and supply.

\section{BACKGROUND STRUCTURE OF TALC PATTERN}

Concerning the TALC pattern and stages, proposed the s-shaped logistic curve to explain tourist area life cycle, but at the same time he stressed (Butler 1980,11) that: "the shape of the curve must be expected to vary for different areas, reflecting variations in such factors as rate of development, government policies, and number of similar competing areas." 
ToSEE - Tourism in Southern and Eastern Europe, Vol. 6, pp. 343-356, 2021.

M. Hell: MODELLING DYNAMICS OF THE TALC WITH SYSTEM DYNAMICS METHODOLOGY ...

Development of a tourist destination as a system is usually seen as the result of the two interrelated subsystems, e.g. supply and demand (Hall 2005; Jakulin 2016; etc.). This implies existence of three important considerations contributing to the dynamics of a destination, being: changes in visitor preferences and needs (demand conditions), gradual deterioration and possible replacement of physical assets and facilities (supply conditions), and change or disappearance of original natural and cultural attractions responsible for the area's initial popularity (supply-demand interaction) (Fritz 1989). This research has intend to extend the model by approaching it from both demand and supply sides, for which a combination of DPSIR (Drivers, Pressures, States, Impacts and Response) framework and system dynamics methodology will be used.

\subsection{Demand side}

Ever since Butler's seminal work (Butler 1980) was published, most of the researchers dealing with the TALC model (Haywood 1986; Di Benedetto and Bojanic 1993; Lundtorp and Wanhill 2001, etc.) approached it from the demand side. As explained by Cole, this evolutionary path is represented with an $\mathrm{S}$ shaped curve associated with the logistic function: $d V / d t=\mathrm{kV}(M-V)$. $V$ represent the number of visitors in time $t$, with the maximum number of visitors $M . K$ is an empirically derived parameter represents the "telling" rate, or the "spread of knowledge of the resort" (Cole 2012). The term $(M-V)$ determines that, as visitor numbers increase toward the level $M$, the rate of growth decreases which gives rise to the familiar S-shaped curve. Specifically, by the time knowledge of a given destination is complete. That means, the increase slows down and $V$ approaches $M$ because there will only be a few people receiving the message for the first time. Thus, the most authoritative formulation of the TALC is a demand-side model. Cole further explained that the above situation can be modelling with the "so-called Verhulst equation originally devised in 1838" (Cole 2012). Although originally conceived to describe the Malthusian growth of human populations faced with resource constraints, it has been applied across many natural and artificial systems including touristic ones. This systems characterize with endogenous growth and exogenous constraints, with a corresponding range of interpretations of the variables, their measurement and their meaning. In tourism, extended version of the equation has been empirically tested on the cases of the island of Bornholm and the Isle of Man, using long run time series, from 1884 to 1912 and from 1912 to 1967 (without world war II), respectively (Lundtorp and Wanhill 2001; 2006). Results of the study showed that even under the assumption of a uniform market, that ignores the shifting patterns of tourist arrivals, the lifecycle curve can only be a truly representative aggregation if all tourists are repeating their visitation. Otherwise, the lifecycle model represents only a statistical approximation.

To be precise, in the original equation, $d V / d t=k V(M-V)$, the change of the number of tourists in time, $d V / d t$, is the product of the two expressions, e.g. $k \cdot V$ and $(M-V)$. The variable $d V / d t$ indicates change of the number of tourists $\left(d V=V t_{2}-V t_{1}\right)$ in the time interval $\left(d t=t_{2}-t_{1}\right)$. The expression $k \cdot V$ indicates that this change depends on the penetration coefficient $(k)$ and the number of tourists $V$ at time unit $t_{1}$, or in other words, variable $V$ grows exponentially in each subsequent time unit (step), because $d V$ is attributed to variable $V$. The question arises as to how long the variable $V$ (number of 
ToSEE - Tourism in Southern and Eastern Europe, Vol. 6, pp. 343-356, 2021.

M. Hell: MODELLING DYNAMICS OF THE TALC WITH SYSTEM DYNAMICS METHODOLOGY ...

tourists) will grow. A look on the other expression $(M-V)$ shows that in each subsequent time unit its value is reduced. Namely, as $V$ increases in each subsequent time unit, due to the first expression, $k \cdot V$, the second expression, $M-V$, decreases. This indicates that the feedback loop (-)FBL2 regulates the growth of the number of visitors in the observed destination, described by $(+)$ FBL1 (see Figure 5a).

\section{Figure 5: Structure of Demand and pattern of behaviour}

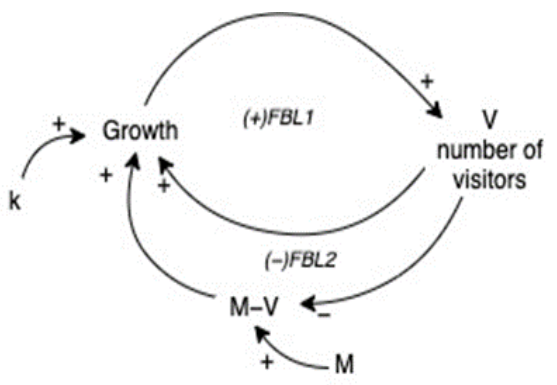

a) Structural scheme of demand

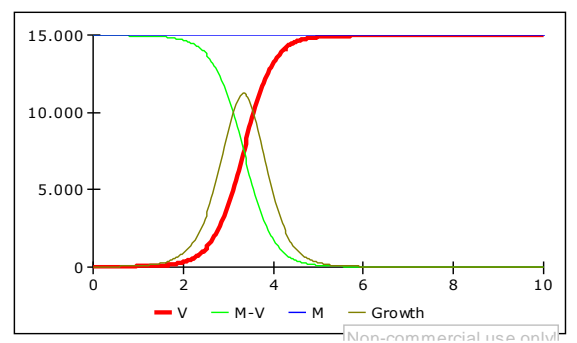

b) Simulation scenario in Powersim of the hypothetical TALC model $\left(\mathrm{V}_{0}=1 ; \mathrm{k}=0,0002\right.$; $\mathrm{M}=15000)$

Source: (Petrić et al. 2020)

Such a combination of $(+)$ FBL1 and (-)FBL2 results in the Butler's S-shape curve (Figure 5.b). In previous studies, the penetration coefficient $k$ and the maximum number of visitors $M$ were observed as constants. According to previous, observing $M$ as constant results in a self-regulation system characterized with sigmoid shape of TALC. However, it has to be borne in mind that destinations develop over time, which is why, in order to get a comprehensive picture of their development, it is necessary to look at $M$ not as a constant, but as a variable. In that case, to understand behaviour of $M$ supply side needs to be analysed.

\subsection{Supply side}

In order to analyse supply side, the DPSIR framework will be employed. According to the DPSIR framework there is a chain of causal links starting with "driving forces" (economic sectors, human activities) through "pressures" (emissions, waste) to "states" (physical, chemical and biological) and "impacts" on ecosystems, human health and functions, eventually leading to political "responses" (prioritisation, target setting, indicators). Describing the causal chain from driving forces to impacts is a complex task, and tends to be broken down into direct links between DPSIR elements (subsystems of indicators). 
ToSEE - Tourism in Southern and Eastern Europe, Vol. 6, pp. 343-356, 2021.

Figure 6. Structure of interactions DPSIR subsystems

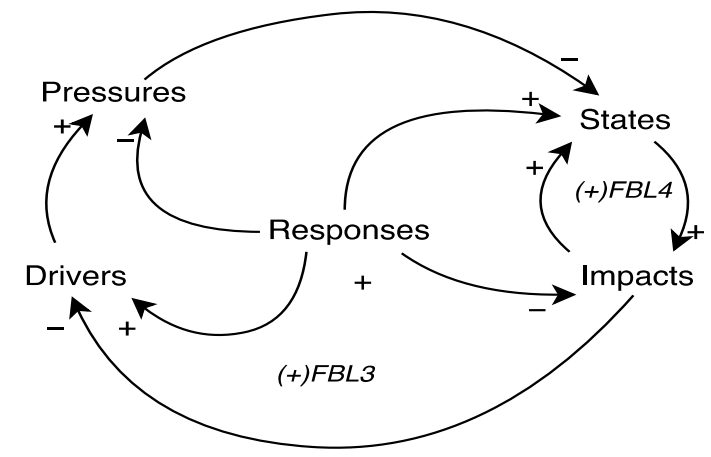

Source: adjusted to (Petrić et al. 2020)

Regarding the framework, drivers (hotels buildings, tourism industry, access to services,...) motivate human activities. More drivers means more human activity which creates more pressure (atmospheric emission, changing landscape, outdoor activities, transportation and touristic product choice etc.). It means positive $(+)$ influence drivers on pressures. More pressure decline state of the natural and built environment and human systems (environment, water, air particulate, insects, asthma, stress, obesity...) what means negative $(-)$ influence on states. In regard to definition of impacts and state, worse state of the natural and built environment and human systems (environment, water, air particulate, insects, asthma, stress, obesity...) cause worse effects of quality and functioning of the ecosystem (climate regulation, disease $\&$ pest regulation, economic prosperity, job production), i.e. positive $(+)$ influence states on impacts. Worse effect of quality and functioning of ecosystem (impacts) decreases drivers i.e. motivation for human activity. It means that negative influence $(-)$ has an impacts on drivers. Described structure is closes the positive $(+)$ FBL3. Exclude of responses describe natural dynamics behaviour of supply side. Every growth of drivers makes pressures, which decline state and impacts, and finally, during longer time it means exponential decline of observed system quality. Additionally, amplifying effect makes positive $(+)$ FBL4. Worse effect of quality causes worse state of human systems what mins $(+)$ positive influence impacts on human states. With previously described positive $(+)$ influence states on impact $(+)$ FBL4 is closed. It can be concluded that $(+)$ FBL3 and $(+)$ FBL4 represent breaks of supply subsystems. Because of that, it is important to manage destination using responses according with DPSIR framework (Petrić et al. 2020).

\subsection{Demand and supply subsystems' interaction}

For effective destination management, demand and supply subsystem must be analysed together as a whole. So, in this paragraph structure diagram of demand and supply subsystem will be connected. Visitors as actors of the demand subsystem consume products generated by the drivers from supply subsystem. On the other hand, visitors from the demand subsystem by consummation generate pressure in demand subsystem. As presented in the Figure 7, the interaction between the subsystems of supply and 
ToSEE - Tourism in Southern and Eastern Europe, Vol. 6, pp. 343-356, 2021.

demand takes place in their cross section. Simply put; a destination uses drivers to attract visitors; increased number of visitors results in increased pressures. Other elements of DPSIR describe the structure within the very destination system. By increasing pressures, the states worsens and leads to negative impacts, eventually causing negative effects on drivers.

\section{Figure 7: System dynamics approach to explanation of demand and supply subsystems'}

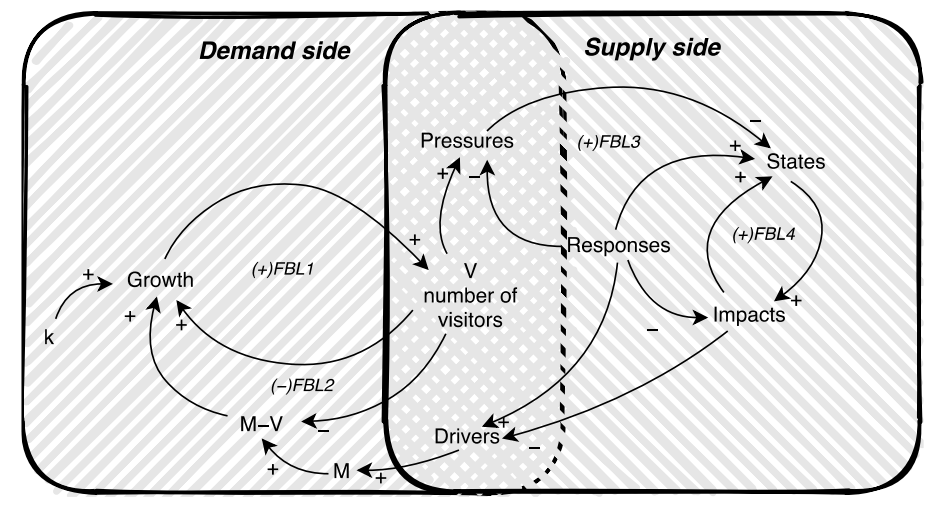

Source: adjusted to (Petrić et al. 2020)

If a number and/or quality of the drivers is reduced, the drop of the variable $M$ on the demand side is expected. To mitigate such a situation, management tools and measures, observed as responses, must be introduced. By introducing responses, pressures caused by an increased number of visitors $(V)$ are reduced; states caused by an increase of pressures are improved; impacts generated by states are decreased, and drivers affected by increased impacts are enhanced.

Based on the above-explained, it may be concluded that the overall shape of the TALC depends on four "main" feedback loops:

- (+) FBL1, described by the exponential growth of visitor arrivals $(V)$;

- (-)FBL2, described by the self-regulating variable $V$, limited by the potential market $(M)$ in a time unit $t$;

- $(+)$ FBL3 and $(+)$ FBL4 described by the exponential growth of the residents' dissatisfaction (resistance) with regard to the growth of visitors.

Reaching the optimal number of visitors may be achieved by managing life cycles in order to establish balance among the four mentioned FBLs. 
ToSEE - Tourism in Southern and Eastern Europe, Vol. 6, pp. 343-356, 2021.

M. Hell: MODELLING DYNAMICS OF THE TALC WITH SYSTEM DYNAMICS METHODOLOGY ...

\section{CONCLUSION}

Conceptualisation of the TALC as a system dynamic model including DPSIR framework provides new insights into demand and supply interactions. Moreover, it enables:

- Analysis of the limits of growth in terms of the number of visitors, by introducing different factors affecting sustainability on the supply side; namely, development of the simulation macro-model enables creation of development prognostic scenarios for tourist destinations, thus supporting better decision-making and eliminating uncertainties typical for the declining stage of the TALC model.

- Determination of the TALC stages' thresholds based on simulation of prognostic scenarios concerning the number of visitors and the duration of each stage. Maximum value of the function (variable) Growth coincides with the change in the shape of the TALC curve. Mathematically, the Growth function represents the first derivative of the variable $V$, which is the rate of change. Thus, the TALC curve can be divided into two periods: the period when the number of visitors grows and the period when it falls. Similarly, through the second derivation, it is possible to observe the acceleration of the change, which allows the TALC curve to be divided into more stages. In the research by (Lundtorp and Wanhill 2001), this approach was applied up to the fourth derivation, but with only the demand side being observed. Extending the simulation model to the supply side may help in determining the causes/logic lying behind the threshold of each of the stages. Simply, instead of the stages being analysed based on the shape of the life cycle curve, the curve can be shaped according to the analysed life cycle stages' characteristics.

- By introducing indicators with regard to both, the DPSIR framework and the feedback loops through the demand side, the presence of a circular impact on the supply side can be examined.

Despite its conceptual nature, applying this model on a specific case (destination) may help managers to properly analyse the interactions between demand and supply side indicators and to introduce proper tools to reduce pressures and eventually contribute to a destination's sustainability and resilience. However, it has to be borne in mind that each destination differs from the others, and so is its DPSIR framework and related indicators. This may also be considered a potential gap of the model. However, the indicators to be chosen must appropriately delineate the state of the art of the D-P-S-and I variables within a destination, in order to introduce the most proper R (responses), i.e. policies.

\section{REFERENCES}

Atkins, J.P., Burdon, D., Elliott, M. and Gregory, A.J. (2011), "Management of the marine environment: Integrating ecosystem services and societal benefits with the DPSIR framework in a systems approach", Marine Pollution Bulletin, Vol. 62, pp. 215-226 https://doi.org/10.1016/j.marpolbul.2010.12.012

Baggio, R., "Symptoms of Complexity in a Tourism System", Tour. Anal., Vol. 13, No. 1. pp.1-20. https://doi.org/10.3727/108354208784548797

Baranger, M. (2010), "Chaos, Complexity, and Entropy - A Physics Talk for Non-Physicists", Center for Theoretical Physics, Laboratory for Nuclear Science and Department of Physics Massachusetts 
ToSEE - Tourism in Southern and Eastern Europe, Vol. 6, pp. 343-356, 2021.

M. Hell: MODELLING DYNAMICS OF THE TALC WITH SYSTEM DYNAMICS METHODOLOGY ...

Institute of Technology, Cambridge and New England Complex Systems Institute, Available online: https://necsi.edu/chaos-complexity-and-entropy (Accessed on 8 May 2021).

Berkhout, F., (1996), "Life Cycle assessment and Innovation in Large Firms", Business Strategy and the environment, Vol. 5, No. 3, pp. 145-155. https://doi.org/10.1002/(SICI)10990836(199609)5:3<145::AID-BSE65>3.0.CO;2-P

Bidone, E.D. and Lacerda, L.D. (2004), "The use of DPSIR framework to evaluate sustainability in coastal areas. Case study: Guanabara Bay basin, Rio de Janeiro, Brazil”, Reg. Environ. Chang, Vol. 4, pp 5-16. https://doi.org/10.1007/s10113-003-0059-2

Bradley, P. and Yee, S. (2015), "Using the DPSIR Framework to Develop a Conceptual Model: Technical Support Document", US Environmental Protection Agency, Office of Research and Development, Atlantic Ecology Division, Narragansett, RI. EPA/600/R-15/154. Available online: http://www.epa.gov/nscep/index.html (Accessed on 8 May 2021).

Butler, R. (1980), "The concept of a tourist area cycle of evolution: Implications for management of resources", Canadian Geographer Vol. 24, No. 1, pp. 5-12. https://doi.org/10.1111/j.1541-0064.1980.tb00970.x

Butler, R. (2006), "The origins of the Tourism Area Life Cycle", in Butler, R. (ed), The Tourism Area Life Cycle, Applications and Modifications, Channel, View Publications, Clevedon, pp. 13-26.

Butler, R. (2011), "Tourism Area Life Cycle" in: Cooper, C. (ed), Contemporary Tourism Reviews, Goodfellow Publishers Limited, Oxford, available at: https://www.ibtcl.co.uk/web_documents/toursim_area_life_cycle_original.pdf (accessed on 8 May 2021)

Cole, S. (2012), "Synergy and congestion in the tourist destination life cycle", Tourism Management. Vol. 33 No. 5, pp. 1128-1140. https://doi.org/10.1016/j.tourman.2011.11.018

Cruz, M.S. and Peñarrubia Zaragoza, M.P. (2019), "Analysis of the accommodation density in coastal tourism areas of insular destinations from the perspective of vertourism”, Sustainability, Vol. 11, No. 11. pp. 3031. https://doi.org/10.3390/su11113031

Dealbuquerque, K. and Mcelroy, J.L. (1992), "Caribbean small-island tourism styles and sustainable strategies", Environmental Management, Vol. 16, No. 5, pp. 619-632. https://doi.org/10.1007/BF02589017

Di Benedetto, C.A. and Bojanic, D.C. (1993), "Tourism area life-cycle extensions", Annals of Tourism Research, Vol. 20, No. 3, pp. 557-570. https://doi.org/10.1016/0160-7383(93)90009-R

Diedrich, A., and García-Buades, E. (2009) "Local perceptions of tourism as indicators of destination decline", Tourism Management, Vol. 30, No. 4, pp. 512-521. doi: 10.1016/j.tourman.2008.10.009

Fritz, R.G. (1989), "Strategic Planning with a Systems Dynamics Model for Regional Tourism Site", The Review of Regional Studies, Vol. 19, No. 1, pp. 57-71, Available at: https://search.proquest.com/openview/c0be2f94fa3d689174e337d305a35a2f/1?pqorigsite $=$ gscholar $\&$ cbl $=2028849$ (Accessed, 8 May 2021)

Gabrielsen, P. and Bosch, P. (2003), "Environmental Indicators: Typology and Use in Reporting", Copenhagen: European Environment Agency, Available online: https://www.eea.europa.eu/publications/TEC25 (Accessed on 8 May 2021)

Haberl, H., Gaube, V., Díaz-Delgado, R., Krauze, K., Neuner, A., Peterseil, J., Plutzar, C., Singh, S.J. and Vadineanu, A. (2009), "Towards an integrated model of socioeconomic biodiversity drivers, pressures and impacts. A feasibility study based on three European long-term socio-ecological research platforms", Ecol. Econ., Vol. 68, pp. 1797-1812.

Hall, C.M. (2005), Rethinking the Social Science of Mobility, Pearson Education Ltd, Harlow.

Haywood, K.M. (1986), “Can the tourist area life-cycle be made operational?”, Tourism Management, Vol. 7 , No. 3, pp. 154-167. https://doi.org/10.1016/0261-5177(86)90002-6

Hell, M. and Petrić, L. (2021), "System Dynamics Approach to TALC Modelling”, Sustainability, Vol 13, No. 9, pp. 4803. https://doi.org/10.3390/su13094803

Jakulin, T.J. (2016), "Systems approach for contemporary complex tourism systems", International Journal for Quality Research, Vol. 10, No. 3, pp. 511-522. doi: 10.18421/IJQR10.03-05

Karageorgis, A.P., Kapsimalis, V., Kontogianni, A., Skourtos, M., Turner, K.R. and Salomons, W. (2006), "Impact of 100-year human interventions on the deltaic coastal zone of the Inner Thermaikos Gulf (Greece): A DPSIR framework analysis”, Environ. Managament, Vol. 38, pp. 304-315.

Karplus, Y. and Krakover, S. (2005), "Stochastic multivariable approach to modelling tourism area life cycles", Tourism and Hospitality Research, Vol. 5, No. 3, pp. 235-253. https://doi.org/10.1057/palgrave.thr.6040023

Koundouri, P, Rault, P.K., Pergamalis, V., Skianis V. and Souliotis, I. (2016), "Development of an integrated methodology for the sustainable environmental and socio-economic management of river ecosystems", Sci Total Environ., Vol. 540, pp. 90-100.

Lundtorp, S. and Wanhill, S. (2001), "The resort lifecycle theory. Generating Processes and Estimation", Annals of Tourism Research, Vol. 28, 947-964. https://doi.org/10.1016/S0160-7383(00)00080-3 
ToSEE - Tourism in Southern and Eastern Europe, Vol. 6, pp. 343-356, 2021.

M. Hell: MODELLING DYNAMICS OF THE TALC WITH SYSTEM DYNAMICS METHODOLOGY ...

Lundtorp, S. and Wanhill, S. (2006), "Time Path Analysis and TALC Stage Demarcation”, in Butler, (ed), The Tourism Area Life Cycle, Conceptual and Theoretical Issues, Vol. 2, Channel View Publications, Clevedon, pp. 138-150. https://doi.org/10.21832/9781845410308-017

Maxim L, Spangenberg J.H. and O’Connor, M. (2009), “An analysis of risks for biodiversity under the DPSIR framework", Ecological Economics Vol. 69, pp. 12-23.

Müller, S., Peters, M. and Blanco, E. (2010), "Rejuvenation strategies: A comparison of winter sport destinations in Alpine regions", Tourism, Vol. 58, No. 1, pp. 19-36., available at: https:/hrcak.srce.hr/index.php?show=clanak\&id clanak jezik=85217 (accessed on 8 May 2021)

Odermatt, S. (2004,) "Evaluation of Mountain Case Studies by Means of Sustainability Variables". Mt. Res. Dev., Vol. 24, pp. 336-341.

Petrić, L., Mandić, A., Pivčević, S., Škrabić Perić, B., Hell, M., Šimundić, B., Muštra, V., Mikulić, D., and Grgić, J. (2020), Report on the most appropriate indicators related to the basic concepts. Deliverable 4.1 of the Horizon 2020 project SmartCulTour (GA number 870708), published on the project web site on September 2020: http://www.smartcultour.eu/deliverables/

Pivčević, S., Petrić, L. and Mandić, A. (2020), "Sustainability of Tourism Development in the MediterraneanInterregional Similarities and Differences", Sustainability, Vol. 12, No. 18, pp. 7641 https://doi.org/10.3390/su1218764

Prideaux, B. (2000), "The resort development spectrum - a new approach to modelling resort development", Tourism Management, Vol. 21, No. 3, pp. 225-240. https://doi.org/10.1016/S0261-5177(99)00055-2

Richardson, G. P., Pugh, A.L. (1981), Introduction to System Dynamics Modelling with DYNAMO, MIT Press, , Cambridge, MA, United States.

Richarson, G.P. (1996), "Problems for future of system dynamics", System Dynamics Review, Vol. 12, No. 2, pp 141-157. https://doi.org/10.1002/(SICI)1099-1727(199622)12:2<141::AID-SDR101>3.0.CO;2-O

Romão, J., Guerreiro, J. and Rodrigues, P. (2013), "Regional tourism development: culture, nature, life cycle and attractiveness", Current Issues in Tourism, Vol. 16, No. 6, pp. 517-534. https://doi.org/10.1080/13683500.2012.699950

Schoenberg, W., Davidsen, P. and Eberlein, R. (2020), "Understanding model behavior using the Loops that Matter method", System Dynamics Review, Vol. 36, No. 2, pp. 158-190. https://doi.org/10.1002/sdr.1658

Siwailam, M., Abdelsalam, H. and Saleh, M. (2019), "Integrated DPSIR-ANP-SD framework for Sustainability Assessment of Water Resources System in Egypt", International Journal of Academic Management Science Research, Vol. 3, No. 3, pp. 1-12, available at: http://ijeais.org/wpcontent/uploads/2019/03/IJAMSR190301.pdf (accessed on 8 May 2021)

Sterman, J.D. (2000), Business Dynamics: System Thinking and Modeling for a Complex World, Irwin/McGraw-Hill, Boston.

Yee, S.H., Bradley, P., Fisher W.S., Perreault, S.D., Quackenboss, J., Johnson, E.D., Bousquin, J. and Murphy, PA. (2012), "Integrating human health and environmental health into the DPSIR framework: A tool to identify research opportunities for sustainable and healthy communities" EcoHealth Vol. 9, pp. 411-426.

Marko Hell, PhD, Associate Professor

University of Split, Faculty of Economics, Business and Tourism

Department of Business Informatics

Cvite Fiskovića 5, 21000 Split, Croatia

+385-21-430716

marko.hell@efst.hr 